Supplement of

\title{
A new method to quantify particulate sodium and potassium salts (nitrate, chloride, and sulfate) by thermal desorption aerosol mass spectrometry
}

Yuya Kobayashi and Nobuyuki Takegawa

Correspondence to: Nobuyuki Takegawa (takegawa@tmu.ac.jp)

The copyright of individual parts of the supplement might differ from the article licence. 


\section{S1 Details of detected ion signals}

We measured all possible $\mathrm{m} / \mathrm{z}$ signals for each compound to identify major $\mathrm{m} / \mathrm{z}$ peaks to be used for quantification, as listed in Table S1. We also measured ion signals at $\mathrm{m} / z 16\left(\mathrm{O}^{+}\right), 28\left(\mathrm{CO}^{+}\right)$, and $44\left(\mathrm{CO}_{2}^{+}\right)$for oxygen-containing compounds (SN, SS, PN, and PS) and found that ion signals at $m / z 44$ were commonly detected. These results suggest that oxygen from

5 SN, SS, PN, and PS particles reacted with organic contamination on the graphite collector or the surface of the graphite itself.

Table S1. Possible $\mathrm{m} / \mathrm{z}$ peaks for the selected compounds. The major $\mathrm{m} / \mathrm{z}$ peaks used for quantification are marked by asterisks.

\begin{tabular}{|c|c|c|c|c|c|c|}
\hline & $\mathrm{SN}$ & $\mathrm{SC}$ & SS & PN & PC & PS \\
\hline \multirow{13}{*}{$m / z$} & $16\left(\mathrm{O}^{+}\right)$ & $23\left(\mathrm{Na}^{+}\right)^{*}$ & $16\left(\mathrm{O}^{+}\right)$ & $16\left(\mathrm{O}^{+}\right)$ & $35\left({ }^{35} \mathrm{Cl}^{+}\right)$ & $16\left(\mathrm{O}^{+}\right)$ \\
\hline & $23\left(\mathrm{Na}^{+}\right)^{*}$ & $35\left({ }^{35} \mathrm{Cl}^{+}\right)$ & $23\left(\mathrm{Na}^{+}\right)^{*}$ & $28\left(\mathrm{CO}^{+}\right)$ & $36\left(\mathrm{H}^{35} \mathrm{Cl}^{+}\right)^{*}$ & $28\left(\mathrm{CO}^{+}\right)$ \\
\hline & $28\left(\mathrm{CO}^{+}\right)$ & $36\left(\mathrm{H}^{35} \mathrm{Cl}^{+}\right)^{*}$ & $28\left(\mathrm{CO}^{+}\right)$ & $30\left(\mathrm{NO}^{+}\right)^{*}$ & $37\left({ }^{37} \mathrm{Cl}^{+}\right)$ & $32\left(\mathrm{O}_{2}^{+}, \mathrm{S}^{+}\right)$ \\
\hline & $30\left(\mathrm{NO}^{+}\right)^{*}$ & $37\left({ }^{37} \mathrm{Cl}^{+}\right)$ & $32\left(\mathrm{O}_{2}^{+}, \mathrm{S}^{+}\right)$ & $39\left({ }^{39} \mathrm{~K}^{+}, \mathrm{C}_{3} \mathrm{H}_{3}{ }^{+}\right)^{*}$ & $38\left(\mathrm{H}^{37} \mathrm{Cl}^{+}\right)$ & $39\left({ }^{39} \mathrm{~K}^{+}, \mathrm{C}_{3} \mathrm{H}_{3}{ }^{+}\right)^{*}$ \\
\hline & $44\left(\mathrm{CO}_{2}^{+}\right)$ & $38\left(\mathrm{H}^{37} \mathrm{Cl}^{+}\right)$ & $44\left(\mathrm{CO}_{2}^{+}\right)$ & $41\left({ }^{41} \mathrm{~K}, \mathrm{C}_{3} \mathrm{H}_{5}^{+}\right)$ & $39\left(\mathrm{~K}^{+}, \mathrm{C}_{3} \mathrm{H}_{3}^{+}\right)^{*}$ & $41\left({ }^{41} \mathrm{~K}, \mathrm{C}_{3} \mathrm{H}_{5}{ }^{+}\right)$ \\
\hline & $46\left(\mathrm{NO}_{2}^{+}\right)$ & $58\left(\mathrm{Na}^{35} \mathrm{Cl}^{+}\right)$ & $48\left(\mathrm{SO}^{+}\right)^{*}$ & $44\left(\mathrm{CO}_{2}^{+}\right)$ & $41\left({ }^{41} \mathrm{~K}, \mathrm{C}_{3} \mathrm{H}_{5}{ }^{+}\right)$ & $44\left(\mathrm{CO}_{2}^{+}\right)$ \\
\hline & $62\left(\mathrm{NO}_{3}{ }^{+}, \mathrm{Na}_{2} \mathrm{O}^{+}\right)$ & $60\left(\mathrm{Na}^{37} \mathrm{Cl}^{+}\right)$ & $64\left(\mathrm{SO}_{2}^{+}\right)$ & $46\left(\mathrm{NO}_{2}^{+}\right)$ & $74\left({ }^{39} \mathrm{KCl}^{+}\right)$ & $48\left(\mathrm{SO}^{+}\right)^{*}$ \\
\hline & $78\left(\mathrm{Na}_{2} \mathrm{O}_{2}^{+}\right)$ & $81\left(\mathrm{Na}_{2}{ }^{35} \mathrm{Cl}^{+}\right)$ & $80\left(\mathrm{SO}_{3}^{+}\right)$ & $62\left(\mathrm{NO}_{3}{ }^{+}\right)$ & & $64\left(\mathrm{SO}_{2}^{+}\right)$ \\
\hline & \multirow[t]{5}{*}{$85\left(\mathrm{NaNO}_{3}^{+}\right)$} & & $81\left(\mathrm{HSO}_{3}^{+}\right)$ & $101\left({ }^{39} \mathrm{KNO}_{3}{ }^{+}\right)$ & & $80\left(\mathrm{SO}_{3}^{+}\right)$ \\
\hline & & & $96\left(\mathrm{SO}_{4}^{+}\right)$ & & & $81\left(\mathrm{HSO}_{3}{ }^{+}\right)$ \\
\hline & & & $98\left(\mathrm{H}_{2} \mathrm{SO}_{4}^{+}\right)$ & & & $96\left(\mathrm{SO}_{4}^{+}\right)$ \\
\hline & & & $142\left(\mathrm{Na}_{2} \mathrm{SO}_{4}^{+}\right)$ & & & $98\left(\mathrm{H}_{2} \mathrm{SO}_{4}^{+}\right)$ \\
\hline & & & & & & $174\left({ }^{39} \mathrm{~K}_{2} \mathrm{SO}_{4}{ }^{+}\right)$ \\
\hline
\end{tabular}

\section{S2 Laser power settings}

We tested various combinations of laser power settings. Kobayashi et al. (2021) showed that the laser power of $\sim 20$ W was sufficient for the desorption of SS, PS, and $\mathrm{MgSO}_{4}$. We investigated optimal conditions for the desorption of the other compounds tested in this study (SN, SC, PN, and PC). We used a two-step laser modulation with a total irradiation time of 60 $\mathrm{s}$ (40 s for the first step and $20 \mathrm{~s}$ for the second step). The laser power for the first step $\left(P_{1}\right)$ was set either at 5, 6.3, or 7.5 W, whereas that for the second step was held constant at $20 \mathrm{~W}$. Figure S1 shows temporal profiles of the radiation temperature of

15 the graphite collector with different laser power settings. 


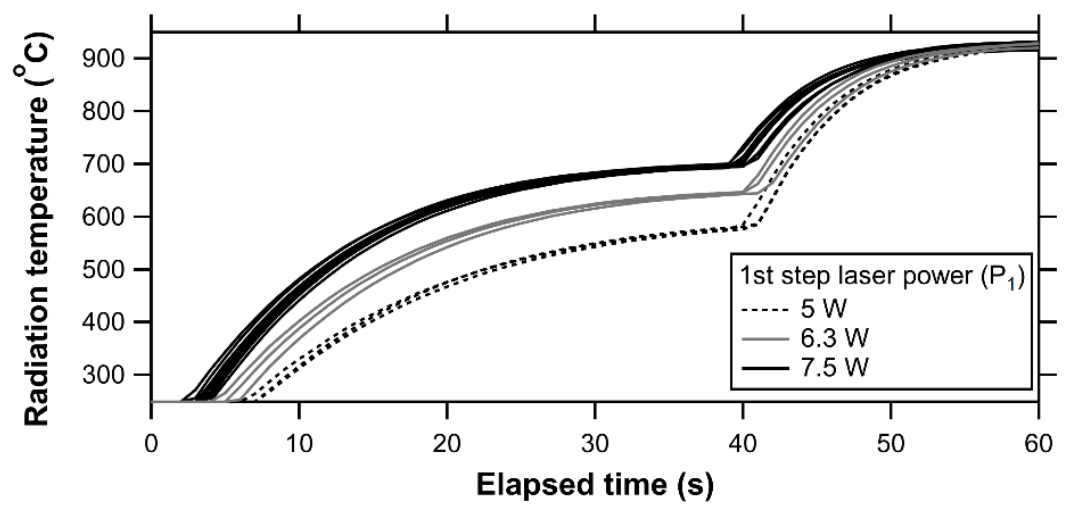

Figure S1: Temporal profiles of radiation temperatures of the graphite collector with different laser power settings as a function 20 of elapsed time since turning the laser on. The ensemble of lines represents repeated measurements on different days.

Figures S2a-c show temporal profiles of ion signals at $m / z 23\left(\mathrm{Na}^{+}\right)$for sodium salts. The ion signals at $m / z 23$ originating from SN particles exhibited bimodal peaks. The second peak at $m / z 23$ tended to appear earlier as the laser power increased, indicating that the laser powers of $5 \mathrm{~W}$ and $6.3 \mathrm{~W}$ were not sufficient for decomposing $\mathrm{NaO}_{\mathrm{x}}$. The laser power of

$257.5 \mathrm{~W}(40 \mathrm{~s})$ may not be sufficient for decomposing $\mathrm{NaO}_{\mathrm{x}}$ (see Figs. $2 \mathrm{a}$ and $5 \mathrm{~b}$ in the main document). Ion signals at $m / z 23$ originating from SC particles exhibited bimodal peaks at $P_{1}=5 \mathrm{~W}$. Ion signals at $m / z 23$ from SS particles did not show significant changes with increasing the $P_{1}$ values.

Figures S3a-c show temporal profiles of ion signals at $m / z 39\left(\mathrm{~K}^{+}, \mathrm{C}_{3} \mathrm{H}_{3}{ }^{+}\right)$for single-component potassium salts. Unlike the results for sodium salts described above, ion signals at $m / z 39$ from PN, PC, and PS particles did not show a

30 significant change with increasing the $P_{1}$ values, although the fluctuation of the $\mathrm{m} / z 39$ signals appeared more significant than that of the $m / z 23$ signals from sodium salts.

Figures $\mathrm{S} 4 \mathrm{a}$ and $\mathrm{S} 4 \mathrm{~b}$ show temporal profiles of ion signals from multi-component sodium or potassium salts. The ion signal at $\mathrm{m} / \mathrm{z} 23$ or 39 could be approximated as a linear combination of the corresponding single-component particles. Larger $P_{1}$ values were preferred for higher vaporization efficiencies, whereas smaller $P_{1}$ values were preferred for better separation

35 of ion signals from different compounds. The separation could be improved if we employ a multi-peak fitting method constrained by ion signals from anions $\left(\mathrm{m} / \mathrm{z} 30\left(\mathrm{NO}^{+}\right), 36\left(\mathrm{HCl}^{+}\right)\right.$, and $\left.48\left(\mathrm{SO}^{+}\right)\right)$. We therefore conclude that $P_{1}=7.5 \mathrm{~W}$ provides the optimal condition for quantifying the sodium and potassium salts tested. 

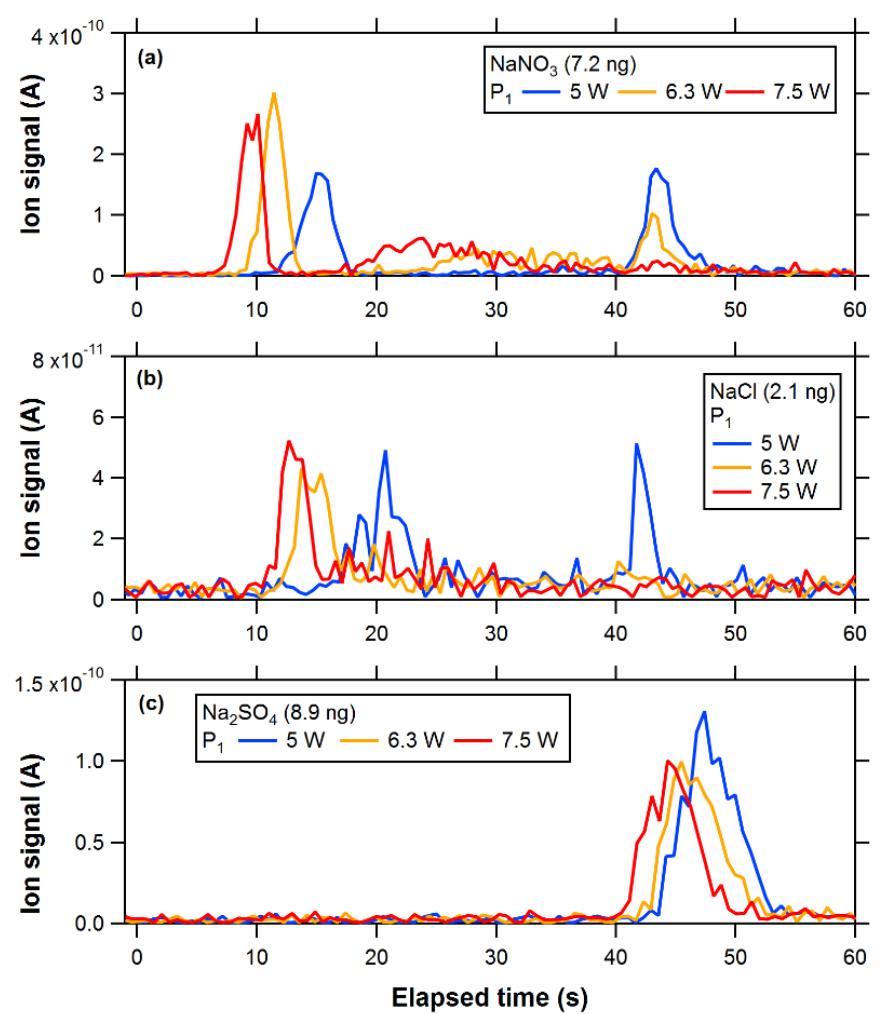

40 Figure S2: Temporal profiles of ion signals at $m / z 23$ originating from single-component (a) SN, (b) SC, and (c) SS particles as a function of elapsed time since turning the laser on with different laser power settings. 

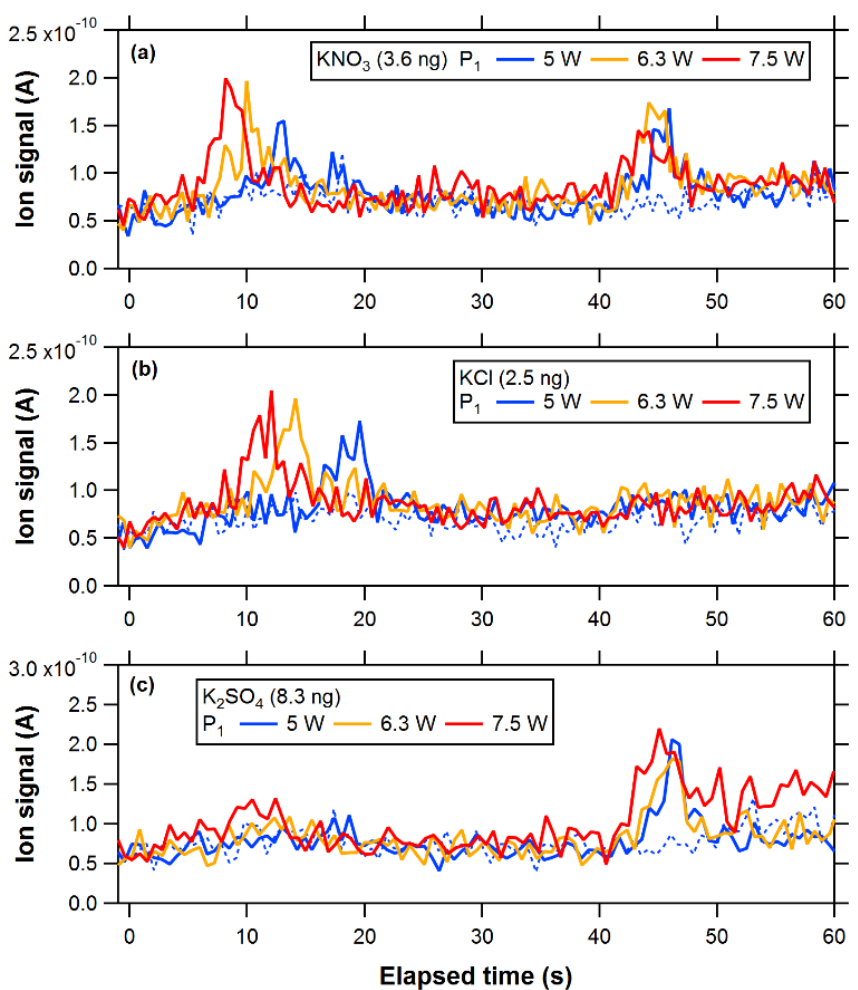

Figure S3: Temporal profiles of ion signals at $\mathrm{m} / \mathrm{z} 39$ originating from single-component (a) PN, (b) PC, and (c) PS particles 45 as a function of elapsed time since turning the laser on with different laser power settings. Dotted lines indicate the results of ZA measurements at $P_{1}=5 \mathrm{~W}$.
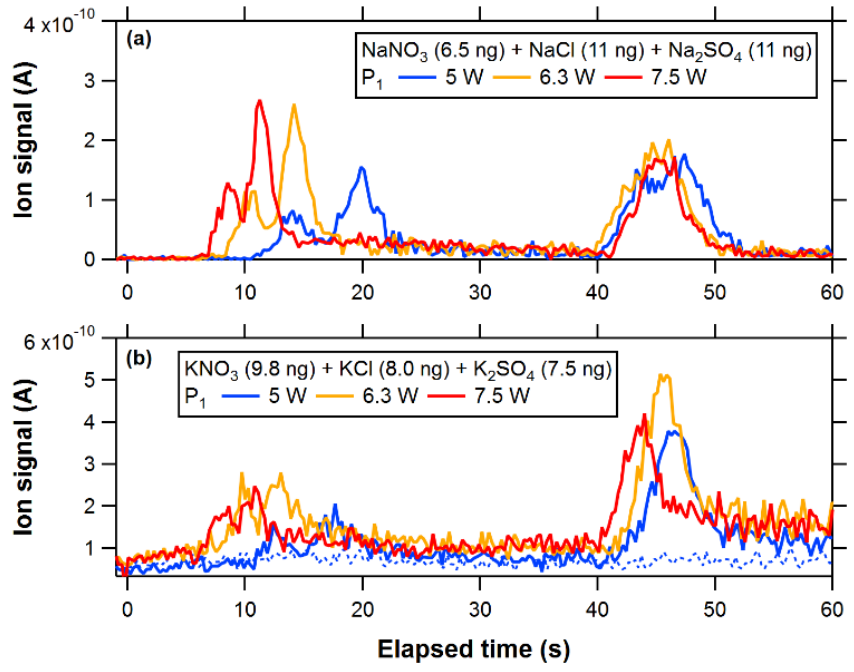

Figure S4: (a) Temporal profiles of ion signals at $\mathrm{m} / \mathrm{z} 23$ originating from multi-component sodium salts with different laser 50 power settings. (b) Same as (a) but for $\mathrm{m} / \mathrm{z} 39$ from potassium salt particles. Dotted lines indicate zero air measurements at $P_{1}$ $=5 \mathrm{~W}$. 


\section{S3 Ammonium salt particles}

Figures S5a-d show the temporal evolution of ion signals at $m / z 30$ and 36 from single-component $\mathrm{NH}_{4} \mathrm{NO}_{3}(\mathrm{AN})$ and $\mathrm{NH}_{4} \mathrm{Cl}(\mathrm{AC})$ particles and externally-mixed $\mathrm{AN}+\mathrm{SN}$ and $\mathrm{AC}+\mathrm{SC}$ particles. Ion signals at $m / z 30$ from AN particles showed a broad peak at 0-13 s. Ion signals at $m / z 36$ from AC particles showed a spiked increase immediately after the laser was turned on with significant tailing up to $\sim 50 \mathrm{~s}$. Ion signals at $m / z 30$ from externally-mixed $\mathrm{AN}+\mathrm{SN}$ particles significantly overlapped at $0-13 \mathrm{~s}$. Ion signals at $m / z 36$ originating from externally-mixed $\mathrm{AC}+\mathrm{SC}$ particles exhibited bimodal peaks.

We also measured single-component $\left(\mathrm{NH}_{4}\right)_{2} \mathrm{SO}_{4}$ (AS) particles and externally-mixed AS + SS particles. Since the ion signals at $m / z 48$ from externally-mixed AS + SS particles were well separated (Kobayashi et al., 2021), we do not show these results. Furthermore, we confirmed that the results for potassium salts were nearly the same as those for sodium salts.

In the current laser power settings, it might be difficult to completely separate ion signals at $\mathrm{m} / \mathrm{z} 30$ originating from AN and SN and those at $m / z 36$ from AC and SC. A multi-peak fitting method could be used for separately quantifying these compounds, as described in the next section.
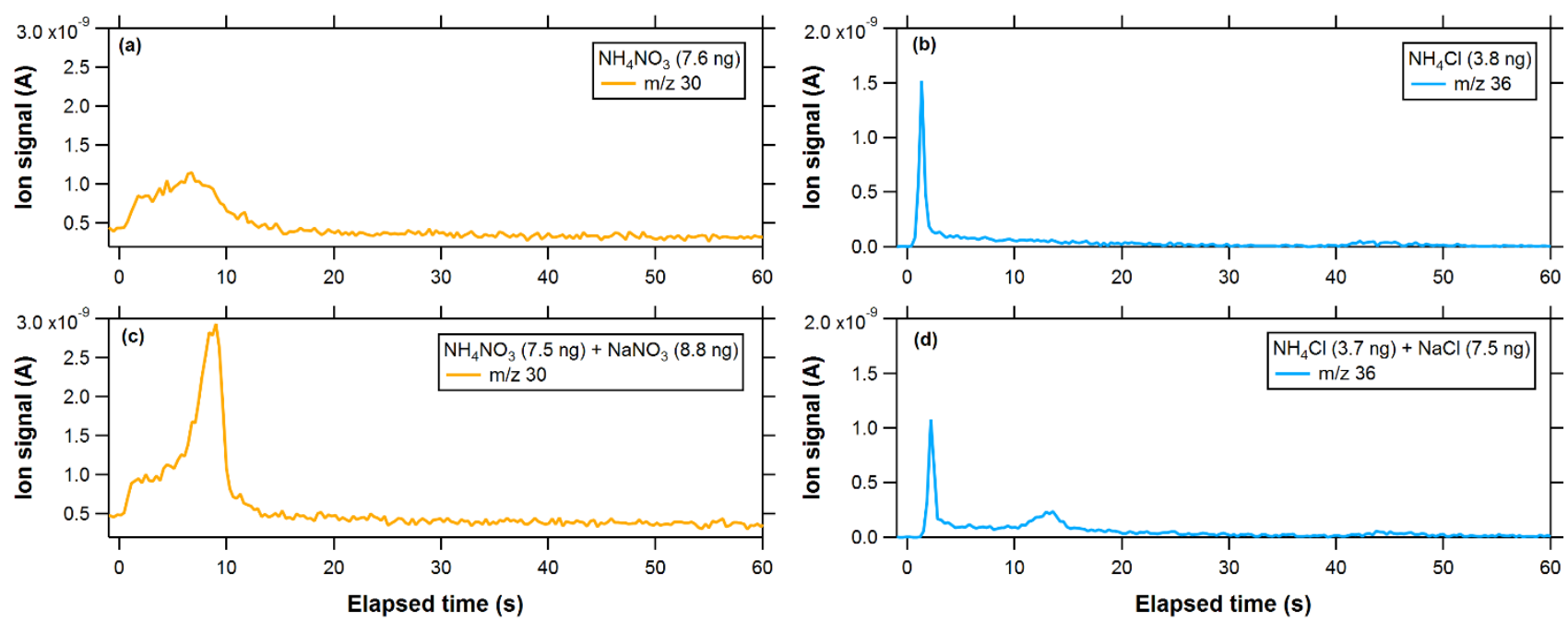

Figure S5: (a) Temporal profiles of ion signals at $m / z 30$ originating from single-component AN particles. (b) Same as (a) but for $\mathrm{m} / z 36$ from single-component AC particles. (c) Temporal profiles of ion signals at $\mathrm{m} / \mathrm{z} 30$ originating from externallymixed AN + SN particles. (d) Same as (c) but for $m / z 36$ from AC + SC particles. 
We used a multi-peak fitting method to estimate the contributions of ion signals at $m / z 23$ from SN and SC particles. Figure S6 shows an example of the multi-peak fitting results. The ion signal data are the same as those used in Fig. 4a in the main document. The first and second peaks, which were attributed to ion signals from SN and SC particles, were fitted by bimodal Gaussian functions. The bimodal Gaussian fitting does not well reproduce the tailing of the ion signals originating

80 from SC particles. Therefore, we reanalyzed the single-component SC data by a unimodal Gaussian function to derive the "approximate" sensitivity for SC particles. The approximate sensitivity value for SC particles incorporated only the Gaussian mode and was lower than the actual sensitivity value because the tailing of the ion signals was excluded. We also reanalyzed the single-component SN data using the same method for consistency. We used the approximate sensitivity for calculating the SN/SC ratios in Fig. 6 in the main document.

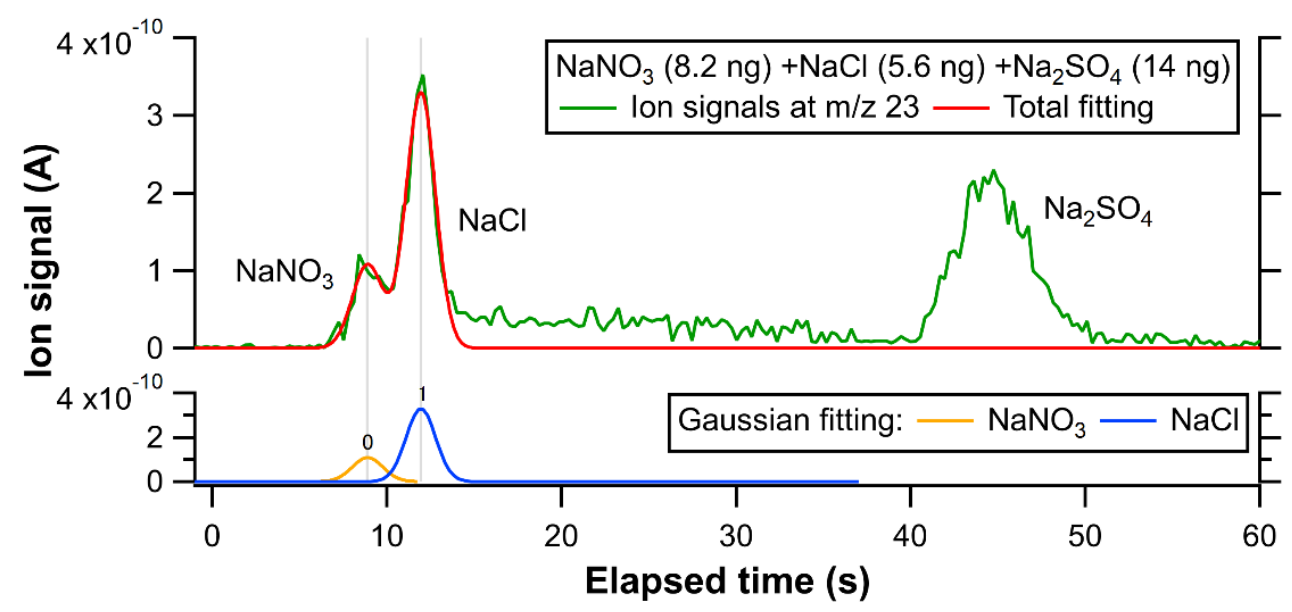

Figure S6: Temporal profiles of ion signals at $\mathrm{m} / z 23$ originating from seawater $+\mathrm{NaNO}_{3}(7.5 \mathrm{mM})$ particles along with a Gaussian fitting for ion signals from SN and SC particles.

\section{S5 Repeated single-component SN and SC data}

Figure S7 shows temporal profiles of ion signals at $m / z 23$ obtained from repeated single-component SN and SC measurements (9 samples). The data from single-component SN and SC particles were normalized to $8.2 \mathrm{ng}$ and $5.6 \mathrm{ng}$, respectively, so that the height of the peaks in Fig. 4a and Fig. S7 could be visually compared. The height of the peaks from multi-component SN and SC (Fig. 4a) particles were $\sim 0.12$ and $\sim 0.35 \mathrm{nA}$, respectively, whereas those from repeated singlecomponent SN and SC particles (Fig. S7) were $\sim 0.28$ and $\sim 0.25 \mathrm{nA}$. Therefore, there might be some matrix effects in the quantification of SN and SC particles when using ion signals at $m / z 23$. 

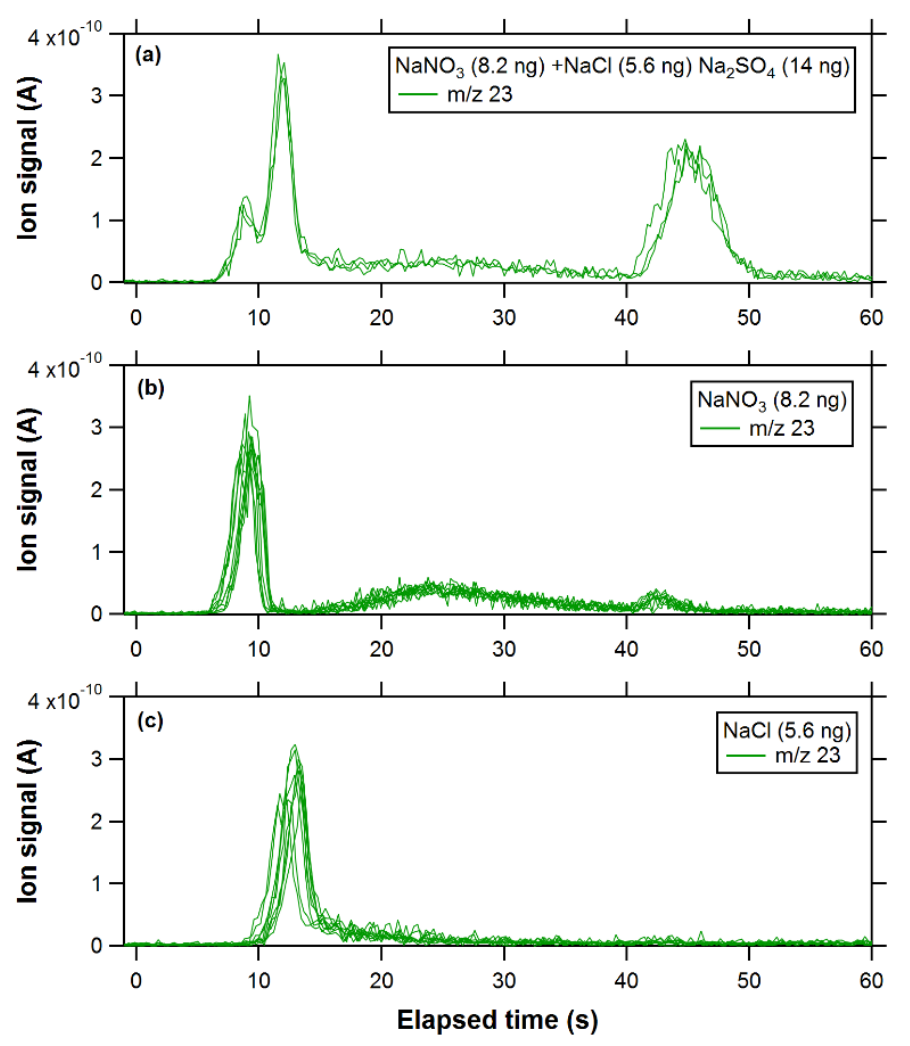

Figure S7: Temporal profiles of ion signals at $\mathrm{m} / \mathrm{z} 23$ originating from (a) multi-component $\mathrm{SN}+\mathrm{SC}+\mathrm{SS}$ particles (the same 100 data as used in Fig. 4a) and single-component (b) SN and (c) SC particles. The data were normalized to match the mass loadings of the multi-component particle data.

\section{S6 Concentrations of the chemical compounds in the seawater sample}

The concentrations of ions $\left(\mathrm{Cl}^{-}, \mathrm{SO}_{4}{ }^{2-}, \mathrm{Na}^{+}, \mathrm{NH}_{4}{ }^{+}, \mathrm{K}^{+}, \mathrm{Mg}^{2+}, \mathrm{Ca}^{+}\right)$and total organic carbon (TOC) in the sampled seawater were measured by ion chromatography analyzer (Dionex ICS-1000, Thermo Fisher Scientific) and TOC analyzer (TOC-VCPH, Shimadzu Corp.), respectively, by Murata Keisokuki Service Co., Ltd., Japan. The seawater sample was diluted by a factor of 100 , and the concentrations in the diluted seawater are shown in Table S2.

Because the seawater sample comprises various ions, it is not straightforward to predict the equivalent molar ratios of the chemical species in aerosol particles generated via dehydration of seawater (or seawater $+\mathrm{SS} / \mathrm{SN}$ ) droplets. The

110 equivalent molar concentrations of selected chemical species were calculated based on their solubility (Table S3). The solubility values were converted to the solubility products $\left(K_{\mathrm{sp}}\right)$ by assuming that the activity coefficients of all ions were unity. The precipitated moles of the chemical species were iteratively calculated by stepwise reduction of water. The equivalent molar concentrations were not determined for minor compounds (denoted as ND in Table 3). Although the above assumption is not valid for highly concentrated solutions, it would not significantly affect the precipitated moles of the major species (SC, 
$115 \mathrm{SN}$, and SS). The calculation results suggest that $\mathrm{PN}, \mathrm{Mg}\left(\mathrm{NO}_{3}\right)_{2}, \mathrm{PS}$, and $\mathrm{MgCl}_{2}$ might have precipitated in the diluted seawater $+\mathrm{SN}$ (or SS) samples, which may cause systematic errors for the SN/SC and SS/SC ratios in the solution. The error bars in Fig. 6 in the main document were based on this estimation.

120 Table S2. Concentrations of major ions and total organic carbon (TOC) in the diluted seawater sample.

\begin{tabular}{ccccccccc}
\hline & $\mathrm{Cl}^{-}$ & $\mathrm{SO}_{4}{ }^{2-}$ & $\mathrm{Na}^{+}$ & $\mathrm{NH}_{4}^{+}$ & $\mathrm{K}^{+}$ & $\mathrm{Mg}^{2+}$ & $\mathrm{Ca}^{2+}$ & $\mathrm{TOC}$ \\
\hline Concentration & 5.1 & 0.25 & 4.8 & $<0.006$ & 0.092 & 0.49 & 0.090 & 17 \\
\hline
\end{tabular}

The dilution factor was 100 . The units of ion and TOC concentrations are $\mathrm{mmol} \mathrm{L}^{-1}$ and $\mu \mathrm{gC} \mathrm{L} \mathrm{L}^{-1}$, respectively.

Table S3. Equivalent molar concentration of the chemical compounds generated via dehydration of seawater droplets (mM).

\begin{tabular}{|c|c|c|c|c|}
\hline & \multirow{2}{*}{$\begin{array}{c}\text { Solubility } \\
\text { (g per } 100 \mathrm{~mL} \text { water) }\end{array}$} & \multicolumn{3}{|c|}{ Equivalent molar concentration (mM) } \\
\hline & & Diluted seawater & $\begin{array}{l}\text { Diluted seawater } \\
+\mathrm{SS}(2.5 \mathrm{mM})\end{array}$ & $\begin{array}{l}\text { Diluted seawater } \\
+\mathrm{SN}(2.5 \mathrm{mM})\end{array}$ \\
\hline $\mathrm{CaSO}_{4}$ & $0.209\left(30^{\circ} \mathrm{C}\right)$ & 0.090 & 0.090 & 0.090 \\
\hline $\mathrm{K}_{2} \mathrm{SO}_{4}$ & $12.05\left(25^{\circ} \mathrm{C}\right)$ & 0.036 & 0.036 & ND \\
\hline $\mathrm{Na}_{2} \mathrm{SO}_{4}$ & $19.4\left(20^{\circ} \mathrm{C}\right)$ & 0.12 & 2.6 & 0.16 \\
\hline $\mathrm{NaCl}$ & $35.9\left(25^{\circ} \mathrm{C}\right)$ & 4.5 & 4.5 & 5.1 \\
\hline $\mathrm{KCl}$ & $35.9\left(25^{\circ} \mathrm{C}\right)$ & ND & ND & ND \\
\hline $\mathrm{MgSO}_{4}$ & $36.4\left(25^{\circ} \mathrm{C}\right)$ & ND & ND & ND \\
\hline $\mathrm{NH}_{4} \mathrm{Cl}$ & $37.2\left(20^{\circ} \mathrm{C}\right)$ & ND & ND & ND \\
\hline $\mathrm{KNO}_{3}$ & $37.93\left(25^{\circ} \mathrm{C}\right)$ & ND & ND & 0.075 \\
\hline $\mathrm{MgCl}_{2}$ & $54.6\left(20^{\circ} \mathrm{C}\right)$ & 0.29 & 0.29 & ND \\
\hline $\mathrm{Mg}\left(\mathrm{NO}_{3}\right)_{2}$ & $72.7\left(25^{\circ} \mathrm{C}\right)$ & ND & ND & 0.34 \\
\hline $\mathrm{CaCl}_{2}$ & $75\left(20^{\circ} \mathrm{C}\right)$ & ND & ND & ND \\
\hline$\left(\mathrm{NH}_{4}\right)_{2} \mathrm{SO}_{4}$ & $75\left(20^{\circ} \mathrm{C}\right)$ & ND & ND & ND \\
\hline $\mathrm{NaNO}_{3}$ & $91.9\left(25^{\circ} \mathrm{C}\right)$ & ND & ND & 1.7 \\
\hline $\mathrm{Ca}\left(\mathrm{NO}_{3}\right)_{2}$ & $138\left(25^{\circ} \mathrm{C}\right)$ & ND & ND & ND \\
\hline $\mathrm{NH}_{4} \mathrm{NO}_{3}$ & $214\left(25^{\circ} \mathrm{C}\right)$ & ND & ND & ND \\
\hline
\end{tabular}

125 The chemical compounds are sorted by the sequential order of the solubility. The solubility data were taken from Nagakura et al. (1998). ND: Not determined. 